\title{
El lugar de lo real: la poesía del cono sur en los años sesenta*
}

\author{
Place of the real: poetry of the southern cone in the nineteen sixties

\section{Óscar Galindo V.} \\ Instituto de Lingüística y Literatura, Universidad Austral de Chile, Valdivia, Chile. \\ Correo electrónico: ogalindo@uach.cl
}

Este artículo indaga en la poesía del cono sur de Hispanoamérica (Argentina, Chile y Perú), con la finalidad de contribuir a la definición del horizonte de preferencias y de las mutaciones y migraciones disciplinarias que han afectado el discurso poético a partir de los años 60 . Desde el punto de vista histórico-literario asistimos en la primera etapa a la clausura del paradigma estético de las vanguardias históricas, dando lugar a un realismo de nuevo cuño, primero, y a un experimentalismo interdisciplinario en una segunda etapa.

Palabras clave: postvanguardia, mutación disciplinaria, heterogeneidad, poesía peruana, poesía chilena, poesía argentina.

This article explores the poetry in the Spanish-American Southern cone (Argentina, Chile and Peru), with the purpose of contributing to define the horizon of preferences and the disciplinary mutations and migrations that have affected the poetic discourse since the 1960's. From the point of view of literary history, in a first stage we witness the closure of the aesthetic paradigm of historical avant-gardes, which gives rise to a new-style realism, first, and to an interdisciplinary experimentalism in a second stage.

Key words: post avant-garde, disciplinary mutation, heterogeneity, Peruvian poetry, Chilean poetry, Argentine poetry.

\section{PARA COMENZAR}

La incorporación al repertorio literario (Even-Zohar 1999) del cono sur hispanoamericano de diversos registros y modelos textuales de manera desjerarquizada en 1954. Nicanor Parra (1914) publica Poemas y antipoemas y en el mismo año el poeta visual argentino Edgardo Antonio Vigo (1928-1997) realiza sus primeras instalaciones de objetos poéticos; el poeta peruano Jorge Eduardo Eielson (1924-2006) inicia una compleja obra multidisciplinar. A ellos se suman luego poetas como Enrique Lihn

\footnotetext{
* Este artículo forma parte del proyecto de investigación FONDECYT 1070208 "Migraciones y mutaciones en la poesía hispanoamericana actual del cono sur (Argentina., Chile, Perú. 1960-2000)”. Investigador responsable: Óscar Galindo V.; coinvestigadora: Claudia Rodríguez M.
} 
(1929-1988) o Leonidas Lamborghini (1927-2009), representativos de esta decisión de seguir tensionando el lenguaje hasta sus últimas posibilidades. Por medio de estos y otros aportes sobreviven a la crítica demoledora que sufren las vanguardias históricas, la preferencia por la experimentación, los cruces entre diversas disciplinas y la construcción de nuevas formas de representación de lo real. La clausura de la vertiente hermética y surrealista de la segunda vanguardia no fue obstáculo para que escritores y artistas visuales continuaran explorando en una tradición distinta más cercana a la poesía moderna anglosajona. La escucha, la recepción crítica no fue, sin embargo, afortunada para la mayor parte de ellos. El contexto social y político reclamaba otras urgencias y otros lenguajes que identificaran discurso poético y discurso público y esta perspectiva pareció imponerse. La poesía dominante en los 60, por lo mismo, fue leída habitualmente por su tono más conservador, por su búsqueda de identidad entre lenguaje poético y lenguaje político, y por la representación de los espacios íntimos de la cotidianidad o incluso de la domesticidad ${ }^{1}$.

Sin embargo, será precisamente en estos años, sobre todo en Perú, que se abrirá espacio un tipo de construcción poética definido por la interdisciplinariedad y la ambigüedad disciplinaria, resultado de la incorporación de estrategias y procedimientos de registro provenientes de las ciencias sociales (antropología, sociología, historiografía preferentemente $)^{2}$ y de la cultura en general. En cierto modo, la discusión sobre la representación de lo real, en conjunto con la emergencia de nuevos problemas en el campo de las ciencias sociales, provocará tipos de textualidad caracterizados por la migración de disciplinas desde otros saberes hacia la poesía. A esta dimensión se suman otras que permiten complejizar el escenario literario. Primero, la utilización de registros poéticos provenientes del habla o de la cultura popular, como ocurre preferentemente en el caso argentino: el tango, los mass media, la cultura de masas, influidos por el arte pop, la Beat Generation, y, en general, la poesía moderna angloamericana. Segundo, la subterránea experimentación entre distintos lenguajes artísticos, en especial las artes visuales y la poesía. Así a principios de los años 70 comienza a consolidarse una poética neovanguardista que en su intento por recuperar el proyecto arte-vida recurre a los restos y poluciones de las vanguardias históricas. Se abre así un contexto nuevo que permite la incorporación de sujetos múltiples, descentrados, a veces marginales, traumáticos y periféricos.

\footnotetext{
${ }^{1}$ El corpus por el que puede transitar un lector informado está constituido inicialmente por poetas como Leonidas Lamborghini, Juan Gelman, Francisco Urondo, Alejandra Pizarnik, Néstor Perlongher, Olga Orozco, Daniel Freimberg (Argentina); Oscar Hahn, Gonzalo Millán, Juan Luis Martínez, Raúl Zurita, Carmen Berenguer, Elvira Hernández, José Angel Cuevas (Chile); Antonio Cisneros, Blanca Varela, Javier Heraud, Carlos Germán Belli, Jorge Pimentel, Rodolfo Hinostroza, Enrique Verástegui, José Watanabe, Eduardo Chirinos, Carmen Ollé (Perú). Desde este límite se puede avanzar hacia el corpus de las décadas posteriores, pues estimamos que, más allá de las especificidades puntuales de los procesos, los principales cambios en el sistema literario tienen su origen en la clausura de los proyectos originales de las vanguardias históricas y en la emergencia de paradigmas que genéricamente se han denominado postmodernos o postvanguardistas.

2 Para el caso de la poesía peruana, Araujo León señala que es a partir de Cisneros, Hinostroza y Lauer que ingresan los conceptos de construcción poética, transculturalidad y fragmentación, provenientes de Pound, Eliot y Lowell, entre otros, caracterizada por el uso del verso largo, de tono salmódico y por un concepto de visualidad y de narratividad que no se vio en la poesía anterior. Se trata de una escritura que "nos revela realidades comprobables ya por la vivencia cotidiana o bien a través de la lectura de la historia y de la cultura (antropología, sociología, política, etc.)". Esta idea sobre la poesía peruana bien podría ampliarse a la poesía hispanoamericana de avanzada (2000: 22).
} 
En las próximas páginas nos detendremos en la poesía escrita alrededor de los años 60 en Argentina, Chile y Perú, buscando establecer en su repertorio dominante los procesos de entrecruzamiento del discurso poético con otros discursos. Se trata de un repertorio textual caracterizado, en consecuencia, por procesos de mutación disciplinaria y genérica, de acentuación de claves realistas e "impuras" de representación y de una dimensión subjetiva testimonial, que cuestiona la relación entre escritura y poder y entre escritura y representación.

\section{LA INVASIÓN DE LO REAL}

Lo real ha invadido lo real, en eso estamos todos de acuerdo, en que no hay escapatoria posible (Enrique Lihn, Escrito en uba, 1969)

1. Poesía y ciencias sociales. Tal vez los elementos más innovadores de la poesía del cono sur a partir de mediados de siglo XX se caracterizan por un proceso de migraciones y mutaciones disciplinarias que descentran el discurso poético hibridándolo con otras formaciones discursivas producto de nuevos mecanismos de representación y referencialidad ${ }^{3}$. En su momento de emergencia supone la instalación de un sujeto que testimonia su cotidianidad e incorpora múltiples registros lingüísticos y culturales de manera desjerarquizada. Desde una perspectiva interdisciplinaria es posible encontrar la presencia de textos fundados en procedimientos propios de las ciencias sociales, por medio de la cita, la fuente documental, el collage; de las ciencias y filosofías del lenguaje, preferentemente por medio de la ampliación del texto a partir de los paratextos, en especial los epígrafes y las notas; y de las ciencias naturales y exactas: biología, física, matemáticas, frecuentemente de manera obliterada, irónica y deconstructiva. Esta mirada sería impensable sin el aporte primero subterráneo y

\footnotetext{
3 Como planteamos en otro momento (Galindo 2004) si miramos este proceso interdisciplinario desde la poesía hispanoamericana se pueden advertir dos mecanismos fundamentales: a) la asimilación interdisciplinaria, fenómeno amplio consistente en la producción de textos poéticos recurriendo a problemas, fuentes y resultados que provienen de disciplinas no literarias (historiografía, sociología, filosofía, antropología, ecología, etc.) que son asimilados a las reglas propias del canon poético. Si bien tradicionalmente la literatura ha incorporado supuestos provenientes de otros campos del saber (historiografía para la novela histórica; psicología para la novela psicológica; método experimental para la novela naturalista, etc.), su incorporación ha resultado de un proceso complejo de asimilación, que permite asegurar la integridad de la literatura como formación discursiva. b) la mutación disciplinaria, esto es, la incorporación al sistema poético de recursos de producción y estrategias discursivas provenientes de otras disciplinas, preferentemente de las llamadas ciencias sociales, sin que medien estrategias definidas de asimilación. A diferencia del proceso anterior, en que el texto poético asegura las exigencias del género, en este caso el resultado es un tipo de texto híbrido, plural e inestable, con diversos grados de énfasis, en que transitan desde la disciplina original hacia la literatura fragmentos textuales o residuos metodológicos que son incorporados a la producción del texto poético. Este tipo de textualidad, cuyo origen es difícil de definir, se presenta, en el caso de la poesía chilena e hispanoamericana, desde mediados del siglo XX, alcanzando sus niveles de mayor impacto e interés en las últimas tres décadas. Lo anterior provoca un tipo de textualidad caracterizado por la indefinición epistemológica y el hibridismo genérico, en la medida en que la mediación entre una y otra formación discursiva no está asegurada por las reglas propias del campo cultural al que pertenece el nuevo producto, afectando los procesos de producción y recepción (Cf. además Carrasco 2002 y Galindo 2002).
} 
dominante, luego, de una escritura experimental que articula diversas disciplinas y lenguajes artísticos.

La producción de textos recurriendo, de manera arbitraria, a estrategias diseñadas desde el campo de las ciencias sociales para los estudios etnográficos tiene un excelente ejemplo en diversos libros del poeta chileno Enrique Lihn, de la llamada generación del 50. La estrategia es el libro de viaje (al fin y al cabo la más básica y fundamental de las experiencias etnográficas), inaugurada con Poesía de paso (1966), pasando por Escrito en Cuba (1969), París, situación irregular (1977) y Estación de los desamparados (1982), hasta, en un registro local y urbano, El Paseo Ahumada (1983) y La aparición de la virgen (1987). En todos estos textos encontramos una vocación socioantropológica, que concibe el texto poético como una reflexión crítica sobre los mecanismos de representación. El caso más extremo de este tipo de escritura se encuentra en Estación de los desamparados, cuyo procedimiento fundamental es la "transcripción testimonial"4. Como sostiene el propio autor en el prólogo se trata de una "crónica o entrevista privada a la ciudad de Lima", construida a partir del supuesto registro de conversaciones reales sostenidas con amigos peruanos, una "obra de montaje con materiales del natural" (1982: 9).

A partir de los años 60, el poeta peruano Antonio Cisneros (1942) ensaya en sus textos reescrituras históricas (Comentarios reales, 1964), crónicas de viaje (Canto ceremonial contra un oso hormiguero, 1968) o exploraciones testimoniales y antropológicas (Crónica del Niño Jesús de Chilca, 1981). Cisneros en la antología Los nuevos (Ceballos 1967), fundadora en Perú de este nuevo paradigma, ${ }^{5}$ señala:

Olvidaba mencionar la importancia que en nuestros días tiene el aumento de estudiantes y estudiosos de las Ciencias Sociales, el acercamiento antropológico a la realidad y no el puro apriorismo sobre ella; y cómo los pálidos hombres de Letras y Filosofía somos desplazados por aquellas funciones más actuales de las llamadas Ciencias del Espíritu (1967: 15).

Acorde con el tono conversacional propio de la época, la poesía de Cisneros dialoga con los más variados referentes históricos y culturales, plenamente situados desde un punto de vista histórico e incluso autobiográfico.

El impacto de las ciencias sociales en la cultura y la literatura hispanoamericana es innegable en todos sus niveles. Efecto de las discusiones teóricas de la época, pero también de los acontecimientos históricos del período. Fernández Cosman ha advertido su impacto en la poesía peruana de los 60 y especialmente en el grupo "los nuevos". Destaca que antes de esta década se produjeron libros como 7 ensayos de interpretación de la realidad peruana (1928) que se proponían una explicación totalizadora del panorama socioeconómico del Perú: "Pero, a ciencia cierta, la sociología como saber institucionalizado sensu stricto surge en nuestro país a principios de los años

\footnotetext{
${ }^{4}$ Si bien el texto fue publicado en 1982, habría sido escrito al menos una década antes, en el contexto de una serie de viajes realizados por el autor a la ciudad de Lima, que muestra además el flujo de ideas poéticas entre uno y otro país. El uso de procedimientos propios de las ciencias sociales en la poesía de Enrique Lihn lo hemos desarrollado en detalle en un artículo anterior (Galindo 2002).

5 La antología incluye además de la "Presentación" de Ceballos, textos de Antonio Cisneros, Carlos Henderson, Rodolfo Hinostroza, Mirko Lauer, Marco Martos y Julio Ortega, junto a una breve presentación o autopresentación de cada poeta y respuestas de carácter metapoético, a un cuestionario.
} 
sesenta con la publicación de una serie de trabajos como Los dueños del Perú (1964), de Carlos Malpica, La emergencia del grupo cholo (1964), de Aníbal Quijano, Poder y sociedad en el Perú (1967), de François Bourricaud, entre otros" (2001: 55). A lo anterior se suma la creación de especialidades de sociología en las universidades de San Marcos, San Agustín, Católica y Agraria, durante la misma década.

Esta preocupación por una perspectiva sociológica en la producción de textos poéticos se advierte en las diversas entrevistas que anteceden las selecciones de poemas en Los Nuevos, como es el caso del ya mencionado Cisneros, pero también de Rodolfo Hinostroza, Carlos Henderson y Mirko Lauer. La condición peruana es trabajada por Rodolfo Hinostroza (1941) en un complejo sistema intertextual y cultural que le permite trazar originales paralelismos históricos. En la misma antología reafirma este modo situado, hispanoamericano y peruano, de asumir la dimensión transcultural de la escritura poética:

Es muy distinto un desnudo griego que un peruano calato, es lo que se dice. Si, por ejemplo, me apoyo en el Puente de Piedra, miro largamente el río Rímac y medito sobre el tiempo, y Heráclito, y vanitas vanitatum, esto es "un peruano calato". Pero si Eliot mira fluir el Támesis, o contempla las Dry Salvages, e igualmente medita, esto es "un desnudo griego" (Ceballos 1967: 70).

Hinostroza, autor entre otros títulos de Consejero del lobo (1964), Poemas reunidos (1986), El sistema astrológico (1972) y Aprendizaje de la limpieza (1978), publica en 1971 Contra natura, texto en el que se injertan diversas referencias teóricas, científicas, lingüísticas y gráficas, generando un poema codificado en múltiples voces, irónico, desenfadado, pseudocientífico. Sucre (1985: 292) ha destacado el uso de ecuaciones algebraicas, símbolos biológicos, fórmulas del ajedrez y guarismos, con otras significaciones (eróticas, por ejemplo); así como el amplio sistema intertextual literario: Propercio, Dante, Shakespeare, Quevedo, Manrique, Mallarmé, Pound, alterados por el humor o por la doble traducción. Estos elementos permiten la inscripción de su escritura en una tradición altamente erudita que mediatiza su mensaje dentro de coordenadas culturales, creando un sujeto de escritura múltiple que apela a un lector también múltiple. La estrategia utilizada consiste en apelar a registros sonoros, visuales e idiomáticos diversos, creando un efecto escenográfico y "posibilidades de lectura que permiten entender la expansión de las fronteras en la poesía latinoamericana contemporánea" (Mazzotti 1995: 18). El trabajo de Hinostroza es un ejemplo de la articulación entre una escritura que junto con reflexionar sobre la cultura y la política peruana al mismo tiempo explora las relaciones de ésta con la cultura universal, por medio de una textualidad abierta, plural, multiforme y de innegable sello experimental e innovador, al menos en sus primeros libros.

Parte importante de este debate tiene que ver con lo que Guillermo Sucre (1985: 278292) ha llamado "trampas de la historia", al destacar la conflictiva relación que se produce entre poesía e historia en la poesía hispanoamericana a partir de mediados de siglo. En este escenario la historia resulta ser el itinerario de la barbarie, de la involución, la escenificación del caos. De ahí la desconfianza en el discurso historiográfico como discurso de la verdad, para potenciar las posibilidades críticas de un lenguaje poético desconstructor de los mitos del pasado en una escritura democratizadora y plural. Uno de los textos interesantes en esta perspectiva es el poema "Eva Perón en la hoguera" de Leonidas Lamborghini (Partitas, 1972), texto construido exclusivamente 
sobre la base de citas de La razón de mi vida de Eva Perón, lectura relevante para generaciones de argentinos y que aquí asoma con todo un sentido nuevo de carácter paródico, contradictorio y crítico. El texto hace sistema con "Crónica de Lima" de Antonio Cisneros, incluido en Canto ceremonial contra un oso hormiguero (1968), palimpséstico lugar en que coexisten múltiples, abigarradas y desjerarquizadas referencias culturales. "Gambito de rey" de Hinostroza, poema de Contranatura (1971), por su parte, se inserta en una tradición altamente erudita de la cultura occidental, ajena a la inmediatez política, instaurando una figura múltiple y compleja del sujeto escritural fundada en una crítica del lenguaje y sus relaciones con la "impetuosa fantasmagoría" de la realidad: "Algo hay, yo te diré / que te conduce a afirmar el pasado y a repetir un acto equivocado / para sentir que existes /porque eres desdichado por ejemplo/ y es inútil el acto, pero no obstante obligado / de repetir, pudiera ser que en el siguiente ciclo se abran las puertas de la justicia / o de la paz".

2. Poesía y cultura popular. En el caso de la poesía argentina de los 60 , los críticos suelen coincidir en su marcada tendencia inicial al realismo y a las preocupaciones sociopolíticas, así como a una relación más viva con la "lengua hablada"6 (desde Andrés 1969 a Fondebrider 2006 y 2007), pero también supone abrirse a la incorporación de nuevos elementos como la historieta, los mitos cinematográficos, la publicidad y sus slogans, los medios de comunicación masiva (Salas 1975). Algo hay de los aportes anteriores de Joaquín Giannuzzi (1924-2004) y su tendencia al "objetivismo realista". La tensión entre cotidianidad y política es un sello de la promoción que se advierte en Juan Gelman con su realismo-crítico, en Francisco Urondo (1930-1976) con sus vinculaciones entre política y poesía, o en Juana Bignozzi (1937) con el tratamiento lírico de la dimensión de género.

Las indagaciones de los poetas de los 60 se inclinan fundamentalmente por la exploración en un realismo cotidiano, en un lenguaje conversacional poetizado, marcado por el voceo y por una amplia libertad sintáctica. Juan Gelman (1930), fundador del mítico y militante grupo El pan duro, fue la avanzada de esta orientación, que modificó la incorporación de una multiplicidad de discursos y referentes al lenguaje poético. La tendencia narrativa de ecos ginsberianos cuestionaba el realismo socialista. Se trataba, claro está, de otra clase de realismo, lejano de las retóricas militantes y declamatorias propias del género.

Si la sociedad contemporánea tiene como uno de sus componentes la producción y consumo de bienes culturales, la cultura popular de masas desarrolla sus propias claves expresivas y constitutivas de las señas identitarias de una comunidad. Este fenómeno es visible en la sociedad hispanoamericana del siglo XX, lo que lleva a sus poetas a negociar con esos lenguajes y contenidos. La poesía, desde los años 50 en adelante, incorpora de manera sostenida el discurso de la sociedad de masas, en especial a través de su producción y reproducción por los medios de comunicación. Un caso ejemplar en este terreno es el diálogo entre poesía y música popular, especialmente

\footnotetext{
${ }^{6}$ Alfredo Andrés destaca los siguientes rasgos: 1) marcada tendencia al realismo, esto es, a la enunciación directa de hechos y situaciones; 2) ubicación geográfica cuyo centro visible es Buenos Aires; 3) preocupaciones sociopolíticas que afloran constantemente; 4) falta de maestros o agentes polarizadores; y a otro nivel: 5) una línea que muestra la preocupación por considerar a América Latina como un solo e inmenso país; 6) esporádicas preocupaciones por la metafísica (1969).
} 
bolero y tango. El tango cumple la función de mediación entre cultura de masas y discurso poético. Se trata, en todo caso, de una apropiación de claves expresivas propias del género musical para la poesía, lejano muchas veces del habla cotidiana, pero que provocan un efecto de naturalidad y cercanía. Gelman logra precisamente convertir ciertos giros de la música popular en gestos que orientan la decodificación en clave cotidiana. Violín y otras cuestiones (1958) de Gelman es un acontecimiento fundamental en este panorama. Pero poco antes se habían publicado El saboteador arrepentido (1955) y Al público (1957) de Leonidas Lamborghini, poeta que será rescatado en los 70 por su carácter renovador y experimental como se advierte en algunos de sus libros posteriores, de los que Carroña, última forma (2001) es su expresión más radical. Friedemberg ha escrito que su poesía "nace como una ruptura radical o más bien como una radical falta de pertenencia al cuerpo de la poesía argentina existente, en la que con los años terminará por insertarse, no por haber cedido en su propuesta original sino por las modificaciones que, en buena parte, como efecto de la propia existencia de Lamborghini se produjeron en ese cuerpo" (1999: 202). Acertadamente la crítica ha destacado el aporte que hicieron a la poesía de los 60 tres poetas algo mayores. El ya mencionado Leonidas Lamborghini, Joaquín Giannuzzi y César Fernández Moreno (1919-1985), en especial en la presencia de un discurso coloquial y político. La publicación en el año 1963 de Argentino hasta la muerte de Fernández Moreno es un acontecimiento fundamental en el rescate de un discurso antipoético, coloquial e irónico.

Resulta evidente, no obstante, la simplificación que supone leer la poesía argentina de los 60 exclusivamente sobre la base de una poética política o militante, como han destacado Ibarlucía (1986) y Fondebrider (2006). Este último ha sido enfático en cuestionar la imagen unilateral que se ofrece sobre la poesía argentina del período, al confundir discurso poético con discurso político. La definición de la poesía del período como poesía política no sirve ciertamente para explicar la complejidad y heterogeneidad de las propuestas en juego. En su opinión, si bien es cierto que el contexto de la época ayuda a comprender de esta manera el proceso poético y que en algunos poetas como Juan Gelman, Francisco Urondo (1930-1976), Alberto Szpunberg (1940), Roberto Santoro (1939-1977) y Julio Huasi (1935-1987) se observa una marcada coherencia en un tipo de discurso poético que contenga el elemento político, en muchos otros no ocurre lo mismo: "Lo cual no significa necesariamente la ausencia de militancia política, sino más bien una separación de ambos discursos. Tal es el caso de, por ejemplo, Miguel Ángel Bustos, poeta netamente romántico que no cabe, a pesar de su desaparición en manos de la dictadura, en el molde sesentista. Por su parte, Susana Thénon, Alejandra Pizarnik, Giana Siccardi, Juana Bignozzi, Luisa Futoransky y Mario Morales, para citar a unos pocos, son poetas que, a pesar de compartir un cierto tono generacional, tampoco entran en la fórmula aplicada para describir el sesentismo" (2006: 15).

Los más significativos poetas chilenos de los 60 están marcados por la búsqueda de articulación entre lenguaje poético y lenguaje conversacional en sus relaciones con la tradición cultural. De ello forman parte los intentos de Óscar Hahn (1938), Manuel Silva Acevedo (1942), Claudio Bertoni (1946), Carmen Berenguer (1946), Gonzalo Millán (1947) o Cecilia Vicuña (1948). Los elementos fundamentales son la recontextualización de códigos, el rigor autocrítico y autorreferencial, el distanciamiento de lo profético de la poesía social. A diferencia de la poesía argentina, la poesía chilena de 
los 60 fue leída por su gesto de distanciamiento del contexto político inmediato, en tanto su escritura predominantemente apuntaba a escenarios cotidianos y domésticos y a un lenguaje que desdeñaba los cantos inflamados de la revolución. Una poesía que se instala en espacios sensoriales y emotivos posibilitando una mirada diferida sobre las circunstancias políticas y culturales del momento.

Esta preocupación inicial se traduce luego en una opción metacrítica que se expresa en un sentido complementario en la poesía ${ }^{7}$ y el trabajo plástico de Gonzalo Millán (1947-2006), por ejemplo, para quien la escritura llega a significar una ruptura de la noción de analogía y, por ende, de la metáfora como principio constructor del poema. En su perspectiva, el poeta se convierte en un manipulador semiótico de los materiales verbales. La noción de "poesía objetiva" que ha acuñado para referirse a su propia práctica poética supone que, más allá de sus relaciones con el extratexto, el lenguaje mismo es el único referente al que puede apelar la escritura ${ }^{8}$. Millán percibe esta noción como un rasgo de la poesía actual, caracterizada al menos por tres aspectos básicos: la neutralidad del hablante; la poesía como operación sobre el lenguaje, en otras palabras, metapoesía, y el eclecticismo semiótico, es decir, la aceptación de la cultura contemporánea como un escenario en el que se entrecruzan múltiples sistemas comunicativos y artísticos. Su poesía trabaja con un escenario cotidiano y personal, que él mismo percibe como espacios micropolíticos, a propósito de sus trabajos en el terreno de la plástica. Los procesos de representación son tensionados por un sistema poético que tiende a la desestructuración de modelos retóricos convencionales o bien al principio de saturación y acumulación para abordar los espacios públicos (La ciudad, 1979). Ambas dimensiones de su poesía se articulan en un constante ejercicio de agresividad y violencia en el que las víctimas son los sujetos o el mismo lenguaje, al pasar del pensamiento analógico o lógico-racional a otro de asociaciones sensoriales arbitrarias.

Oscar Hahn (1938), por su parte, consigue superar muy tempranamente la identidad entre lenguaje poético y lenguaje conversacional, por medio de una poética neomanierista en que se articulan desjerarquizadamente registros propios de la tradición literaria hispana, en relación con registros populares y referencias a la tradición poética vanguardista. Su escritura es una de las más innovadoras del período al poner el acento en la hibridación y mutación de voces que supone integrar una tradición culta y culterana a la poesía. Textos en apariencia convencionales ocultan y develan

\footnotetext{
7 Su obra se inicia muy tempranamente con un sólido libro “adolescente", Relación personal (1968), casi una década más tarde publica La ciudad (Montreal, 1979, y una reedición con modificaciones en 1994); luego Vida 1968-1982 (1984), Seudónimos de la muerte (1984), Virus (1987), Dragón que se muerde la cola (1987), 5 poemas eróticos (1990). Su obra hasta esa fecha se encuentra reunida en Trece lunas (1997). Sus últimos libros de poemas son Claroscuro (2002), Autorretrato de memoria (2005). Son libros póstumos Veneno de escorpión azul. Diario de Vida y de Muerte (2007) y Gabinete de papel (2008).

8 Una buena explicación de lo que Millán entiende por poesía objetiva es la siguiente: "Poesía objetiva por su preferencia por lo que está ante uno, lo concreto, y por su carácter impersonal, distante, neutro; por el empleo de ese hablante que no vierte directamente sus afectos y sentimientos ni tampoco enjuicia ni comenta. Poesía objetora de una concepción romántica y simbolista de la poesía. Objetora también respecto a la ética tradicional ya que frente a la vergüenza y el pecado reivindica los tormentos y placeres de la sensorialidad, la visible maravilla y el horror de cada día. Poesía que opone a la pureza bella, la imperfección, y a la trascendencia, la materialidad terrestre. Poesía austera en cuanto a la calidad y cantidad de las imágenes que emplea, de la diferencia antes que de la analogía" (Chihuailaf y Eytel 1985: 17).
} 
un sistema de referencias culturales que da cuenta de un sincretismo literariamente no resuelto en Hispanoamérica9 .

3. Poesía y artes visuales. Una corriente menos rescatada es la poesía visual que tiene en Argentina y en los demás países del cono sur una tradición específica. Un antecedente clave para comprender este desarrollo es la poesía concreta, impulsada desde principios de los años 50 por el boliviano-suizo Eugen Gomringer y el grupo brasileño Noigandres. La publicación por los poetas Augusto de Campos, Haroldo de Campos y Dêcio Pignatari del documento Plano-Piloto para Poesia Concreta es un acontecimiento de impacto continental. Su propuesta denominada "isomorfismo" buscaba la producción de una clase de texto construido por igual en los planos sonoro, visual y de significación del material del lenguaje. En Argentina el poeta visual Edgardo Antonio Vigo realiza en el año 1954, a su regreso desde Francia, una singular exposición de objetos de madera encerrados en cajas. La idea era la intervención por parte del público, desafiando la idea de autor y los principios constructivos de la obra plástica y poética. En la década del 60 desarrolla una amplia e interesantísima experiencia de poesía visual. En 1961 funda la publicación Diagonal Cero, coincidente temporalmente y en actitud iconoclasta con Los Huevos del Plata publicada en Montevideo por Clemente Padín (1939), quien ha continuado con una notable labor de difusión de la poesía visual, y más tarde $W C$ y Hexágono 70, difusoras de la "novísima poesía". Propulsor del llamado "arte correo", su propuesta se sintetiza en "Hacia una Poesía para y/o a Realizar" (Pérez Balbi 2007). Contemporáneo en sus experimentos poético-visuales del diario mural El Quebrantahuesos de Parra, Lihn y Jodorowsky, o del poeta peruano Jorge Eduardo Eielson (1924). En Chile el trabajo de Vigo se relaciona con el del poeta visual Guillermo Deisler (1940), autor de trabajos que intersectan diversos géneros y lenguajes: poesía, pop art, publicidad, arquitectura, pintura. Sus aportes escasamente difundidos se articulan con las "Pinturas Aeropostales" de Eugenio Dittborn (1943), con La nueva novela (1977) y La poesía Chilena (1978) de Juan Luis Martínez (1942), autor además de importantes trabajos plásticos, y con “Áreas verdes” (1974) y Purgatorio (1979) de Raúl Zurita (1950), quien ha desarrollado además diversas acciones de arte posteriormente incorporadas a sus distintos libros.

En general, los poetas de los 60 en los tres países inevitablemente proyectan sus preocupaciones desde los problemas de representación del lenguaje poético en su relación con la realidad, a una reflexión experimental sobre el propio lenguaje y su articulación con otras artes y con diversas teorías del lenguaje y de las ciencias en general. Los textos publicados hacia los años 70 coinciden en su interés por resituar claves vanguardistas, dando origen a un complejo sistema de referencias intertextuales que superan largamente el espacio literario. Se trata de una proyección de la razón crítica a la razón científica como posibilidad de construcción de lenguaje poético. La influencia a partir de los años 60 de corrientes lingüísticas y semióticas, estructuralistas y postestructuralistas, así como de la filosofía del lenguaje, es evidente. Se trata de una relación que permea tanto la reflexión metatextual como el amplio sistema de referencias intertextuales transgenéricas de los poemas. En este contexto, reemergen,

\footnotetext{
9 Su obra se inicia con Esta rosa negra (1961), Agua final, 1967, y Arte de morir, 1977, y se encuentra reunida en diversas sumas poéticas como Antología virtual (1996) y Obra poética (2006).
} 
como en la primera vanguardia, las relaciones entre poesía y artes visuales, así como un importante movimiento de poetas visuales en distintos países de Latinoamérica.

La ruptura de los soportes lingüísticos convencionales, como base de la escritura poética, constituye una de las claves de la poesía de vanguardia europea e hispanoamericana. De igual forma, constituye parte del desarrollo del pop art norteamericano, de la poesía concreta y, en síntesis, es inseparable del estado actual de la postvanguardia en sus diversas formas. Dicha ampliación del significante está ligada, por un lado, a la ruptura global de las convenciones románticas de la poesía como expresión personal, pero, por otro, es síntoma de la crisis de los discursos estables en el arte contemporáneo, de la crítica a la institucionalidad artística y de la apropiación del proyecto arte-vida como parte de una visión de crisis de la modernidad. La ruptura de normas, en este sentido, es una metáfora del discurso poético enclaustrado por los márgenes del autoritarismo y supone su ampliación y su liberación por medio de una escritura plural.

\section{PARA CONCLUIR}

El fenómeno de la interdisciplinariedad literaria es un proceso amplio en la poesía hispanoamericana contemporánea, que alcanza en el cono sur, especialmente en Chile y Perú, una dimensión que extrema las exigencias al lector y a todo el sistema literario. Lo anterior provoca zonas de heterogeneidad y frontera de la escritura poética con otros sistemas culturales, especialmente con las demás artes visuales y las ciencias sociales y de la naturaleza. Este proceso irrumpe en los años sesenta con la activa participación de poetas de la promoción del 50 y se proyecta hacia las décadas posteriores. Así la "poesía social" de los 60 muestra en sus aristas más interesantes una exploración en los problemas de representación de la realidad, enriqueciendo y contradiciendo el discurso político dominante. El resultado más frecuente es la asimilación de procedimientos y recursos provenientes de otras disciplinas a la poesía, pero, en este contexto, es posible describir un proceso, probablemente el más innovador, caracterizado por diversos niveles de "mutación disciplinaria". El discurso poético se convierte, de esta manera, en un espacio de integración heterogénea de diversos, permítanme la metáfora, genes semióticos provocando como resultado un híbrido textual y epistemológico. La poesía de los 60 y sus alrededores es la que abre espacio al desdibujamiento del sistema literario provocada por la predominancia de visiones interdisciplinarias y el debilitamiento de la estructura de los géneros tradicionales. Lo anterior genera que la textualidad hispanoamericana se vuelva progresivamente asistémica y heterogénea y los sistemas enunciativos polifónicos, provocando la aparición de personajes textuales que establecen contradictorias relaciones entre sujeto textual y sujeto histórico. Estos procesos de movilidad e indeterminación se producen, de manera más o menos simultánea, en los tres países, provocando debates sobre nuevas nociones de cultura y sociedad y reprocesando el realismo tradicional por medio de nuevas formas de representación y de testimonialidad poéticas. 


\section{OBRAS CITADAS}

Andrés, Alfredo. 1969. El 60. Buenos Aires: Editores Dos.

Araujo León, Oscar. 2000. Como una espada en el aire. Antología documental, testimonial y poética de la generación del 60. Lima: U. Ricardo Palma, Noceda, Mundoamigo.

Carrasco, Iván. 2002. "Interdisciplinariedad, interculturalidad y canon en la poesía chilena e hispanoamericana actual". Estudios Filológicos 37: 199-210.

Ceballos Mesones, Leonidas. 1967. Los nuevos. Cisneros / Henderson / Hinostroza / Lauer / Martos / Ortega. Lima: Universitaria.

Even-Zohar, Itamar. 1999. "Factores y dependencias en la cultura. Una revisión de la Teoría de los Polisistemas". Teoría de los polisistemas (Estudio y compilación M. Iglesias Santos). Madrid: Arco/Libros, 23-52.

Fernández Cosman, Camilo. 2001. Rodolfo Hinostroza y la poesía de los años sesenta. Lima: Biblioteca Nacional del Perú.

Fondebrider, Jorge. 2006. Tres décadas de poesía argentina 1976-2006. Buenos Aires: Libros del Rojas.

2007. Una antología de la poesía argentina (1970-2007). Santiago de Chile: LOM.

Friedemberg, Daniel. 1999. "Herencias y cortes. Poéticas de Lamborghini y Gelman". Historia crítica de la literatura argentina. Noe Jitrik (director). Vol. 10. Susana Cella, directora del volumen. Buenos Aires: EMECE.

Galindo, Óscar. 2002. "Mutaciones disciplinarias en la poesía de Enrique Lihn”. Estudios Filológicos. 37: 225-240.

2004. "Interdisciplinariedades en las poesías chilena e hispanoamericana actuales". Estudios Filológicos. 39: 155-165.

Chihuailaf, Elicura y Eytel, Guido. 1985. "Gonzalo Millán: un poeta objetivista”, Poesía Diaria. 6.

Ibarlucía, Ricardo. 1986. "Crónica de una dispersión”. Diario de poesía. Año I, № 2.

Mazzotti, José Antonio y Zapata, Miguel Ángel. 1995. El bosque de los huesos. Antología de la nueva poesía peruana 1963-1993. México: Ediciones El Tucán de Virginia.

Pérez Balbi, Magdalena. 2009. "Movimiento diagonal cero: poesía experimental desde La Plata (1966-1969). Escaner Cultural. Revista Virtual de Arte Contemporáneo y Nuevas Tendencias. Año 11 № 112 - Enero/Febrero 2009. www.escaner.cl

Salas, Horacio. 1975. Generación poética del 60. Buenos Aires: ECA.

Sucre, Guillermo. 1985. La máscara, la transparencia. México: FCE. 
